\title{
(t)
}

\section{DESENVOLVIMENTO E POBREZA: UMA ANÁLISE CRÍTICA}

Development and poverty: a critical analysis

\section{Luana Souza Siqueira'}

\section{RESUMO}

O presente trabalho propõe uma breve discussão sobre o desenvolvimentismo no enfrentamento à pobreza e seus rebatimentos na literatura do serviço social. Para tanto, está organizado em quatro partes: a visão de pobreza e desenvolvimentismo do Banco Mundial e de Amartya Sen, autor de importante relevância nas agências multilaterais; o debate marxista sobre a pobreza e a sociedade capitalista; as discussões que são apropriadas pelos assistentes sociais e uma breve análise final, considerando o fenômeno da pauperização como algo inerente à sociedade capitalista.

\section{PALAVRAS-CHAVE}

Pobreza. Desenvolvimento. Desigualdade. Combate à Pobreza.

\section{ABSTRACT}

This paper proposes a brief discussion about the developmentalism in facing poverty and its repercussions in the literature of social work. For this purpose, it is organized in four parts: the vision of poverty and developmentalism of World Bank and Amatya Sen, major author in multilateral agencies; the Marxist debate on poverty and capitalist society; the discussions that

\footnotetext{
1 Professora da Escola de Serviço Social da Universidade Federal do Rio de Janeiro (UFRJ) e Pesquisadora de Políticas Públicas, Trabalho e Serviço Social (PPTSS). Doutora em Serviço Social, Mestre em Educação e Serviço Social, Pedagoga e Assistente Social. E-mail: <luanass81@yahoo.com.br>.
} 
are appropriated by social workers; and a brief final analysis, considering the phenomenon of impoverishment as something inherent to the capitalist society.

\section{KEYWORDS}

Poverty. Development. Inequality. Combat Poverty.

Submetido: 21/3/2012

Aceito: $20 / 8 / 2012$

\section{INTRODUÇÃO}

A discussão sobre o desenvolvimentismo no enfrentamento à pobreza é necessário e urgente, nossa preocupação perpassa pela apropriação desse debate no serviço social. Assim apresentaremos: a perspectiva do desenvolvimentismo abordada pelo Banco Mundial (1990; 2000; 2002; 2003) e Amartya Sen (2000; 2001; 2009), o debate histórico-crítico sobre a pobreza e a sociedade capitalista; e os assistentes sociais frente a essa problemática.

Há quem pense a pobreza como produto de um insuficiente desenvolvimento, tendo como causas da pobreza: a) subdesenvolvimento ou insuficiente desenvolvimento econômico; e b) uma fase de crise capitalista.

Neste caso, as formas de enfrentamento passam pelo desenvolvimento econômico: "Fazer crescer o bolo para logo distribuí-lo". Neste sentido a estratégia para tal desenvolvimento orienta-se em função da situação de que se trate: a) para caso do subdesenvolvimento ou $\mathrm{o}$ insuficiente desenvolvimento capitalista, promove-se políticas, serviços sociais e estímulo à produção e ao consumo; b) para o caso de uma crise capitalista, procura-se a superação mediante a redução dos custos de produção (e do valor da força de trabalho), a redução de gasto social do Estado e a Focalização da política social.

Entende-se aqui a pobreza como um problema de escassez, seja produto de um estágio ainda não suficientemente desenvolvido do país (subdesenvolvido), seja resultado de uma fase de crise (em países desenvolvidos). Em ambos os casos a pobreza é pensada como um fenômeno transitório, não estrutural, que representaria um estágio de reduzida produção de bens.

Na verdade, por um lado, o subdesenvolvimento de um país não pode ser visto como condição autônoma de uma nação, mas como 
produto de uma relação do sistema mundial capitalista, como um "[...] desenvolvimento desigual e combinado[...]", conforme Trotsky (1985, p.19), numa relação de dependência entre países centrais e periféricos. Por outro lado, a crise capitalista também não pode ser analisada como uma doença, como um fenômeno externo ao próprio desenvolvimento capitalista; ela representa uma fase necessária da dinâmica cíclica do capitalismo, passando por períodos de expansão, de estagnação e de recessão ou crise, conforme análise de Marx (1980), de Trotsky (1985), Mandel (1980) e Mészáros (2002). Desenvolvimento, expansão e crise são fases de um único processo, estrutural e cíclico do capitalismo. Portanto, as formas de enfrentamento da pobreza que visam promover o desenvolvimento ou que procuram a superação da crise nada podem fazer para a redução da pobreza se tais medidas não vierem acompanhadas de mudanças na distribuição da riqueza, portanto, limites na acumulação de capital.

\section{AS PROPOSTAS DESENVOLVIMENTISTAS DE COMBATE À POBREZA}

\subsection{O Banco Mundial e a política de "alívio à pobreza"}

Num cenário de crescente pobreza, absoluta e relativa, cujo avanço da ofensiva neoliberal imprime um papel para o Estado, mínimo para o social e máximo para o capital (nos termos de NETTO, 1999), as agências multilaterais se consagraram como as mais apropriadas para promover ações e políticas de alívio à pobreza, ou seja: ajuda internacional mediante transferência de capitais e tecnologias. É diante desse contexto que o Banco Mundial vem assumindo a expressão do multilateralismo e se tornando o principal promotor das políticas de combate à pobreza, sobretudo nos países da periferia.

Segundo os documentos produzidos pelo próprio Banco Mundial, entre seus objetivos estão o de fomentar e promover as políticas de combate à pobreza, em articulação com os governos nacionais dependentes da sua ajuda.

A partir da década de 70 o Banco Mundial vem apresentando interesse no trato à pobreza. Marcados por turbulências financeiras, os anos 1980 (segundo surge desse documento; BANCO MUNDIAL, 2007) são denominados de década perdida. Somente em 1990 que 
a pobreza constitui tema central, é um marco nas representações acerca do fenômeno. De acordo com sua introdução, "[...] o presente relatório trata da pobreza no mundo em desenvolvimento - ou seja, trata dos pobres mais pobres do mundo. Busca, em primeiro lugar, medir qualitativa e quantitativamente a pobreza" (BANCO MUNDIAL, 1990, p. 1). Esse relatório a classifica conforme a situação econômica, medida pelo Produto Nacional Bruto (PNB) per capita. Predomina o conceito de pobreza assentado em indicadores econômicos, como a renda per capita. Como aparece no trecho a seguir:

Os grupos de países adotados neste relatório são assim definidos: economias de baixa renda são aquelas com PNB per capita igual ou inferior a U\$545,00 em 1988; economias de renda média são aquelas com PNB per capita superior a $U \$ 545,00$, mas inferior a U\$ 6.000,00 em 1988; economias de alta renda são aquelas com PNB per capita igual ou superior a $U \$$ 6.000,00 em 1988 (BANCO MUNDIAL, 1990, p. 10).

No relatório de 1990, a estratégia do Banco Mundial para reduzir a pobreza "de modo rápido e politicamente sustentável" concentra-se em fatores relacionados: transferência de renda, atividade laborativa e promoção de atividades vinculadas à assistência social. Pois o êxito desta estratégia dependeria dos países clientes seguirem fielmente suas diretrizes, condição indispensável para receber ajuda dos organismos internacionais, como mostra a citação a seguir:

A ajuda externa deveria vincular-se mais estreitamente aos esforços que os futuros beneficiários se mostrassem dispostos a fazer para reduzir a pobreza [...]. Reafirma-se assim a convicção de que a ajuda só funciona bem quando é acompanhada de uma boa estratégia desenvolvimentista (BANCO MUNDIAL, 1990, p. 4).

A proposta do Banco Mundial é de reduzir a pobreza (extrema), de aliviá-la, pois parte do suposto de que "[...] seria possível, com pouco ônus para os países industrializados, obter os recursos externos necessários ao custeio desta estratégia" (BANCO MUNDIAL, 1990, p. 6). Ainda mais se, declaradamente, esta estratégia não exige elevados custos aos países centrais, nem ao capital, nem limites à acumulação capitalista, ela também tem consequências políticas 
para os países periféricos, na medida em que a realização dessas propostas de ajuda internacional para combater a pobreza deixa os países assistidos ainda mais dependentes, financeira e tecnicamente. Ou seja, ao definir como e em que estes recursos serão empregados, a instituição multilateral impõe aos clientes pobres uma determinada modalidade de trabalho e de assistência, elementos-chave da sua proposta de combate à pobreza, assim como exigências e condicionalidades para as políticas econômica e social desses países assistidos. Esta estratégia marcou a política do BM de combate à pobreza nos anos 90.

Passada uma década desde 1990, o Banco Mundial esclarece, no prefácio do World Development Report de 2000/2001, que não atingiu suas metas de redução da pobreza (BANCO MUNDIAL, 2000). Pelo contrário, o número de pobres aumentou tanto na América Latina, no Sul da Ásia e África Subsaariana como nos países da Europa e Ásia Central, em transição para a economia de mercado (BANCO MUNDIAL, 2002, p. 3). A instituição admite as dificuldades em combater a pobreza e sua complexidade.

$\mathrm{Na}$ tentativa de expor melhor o problema, primeiramente, o Banco Mundial apresenta uma breve retrospectiva acerca das distintas estratégias desenvolvimentistas adotadas pelos países, sob sua orientação, nas últimas décadas, afirmando, assim, que:

[...] nos anos 1950 e 1960, muitos consideravam os grandes investimentos em capital físico e infra-estrutura como a principal via de desenvolvimento. Nos anos 1970, aumentou a conscientização de que o capital físico não era suficiente: a saúde e a educação tinham pelo menos a mesma importância... Nos anos 1980, após a crise da dívida, recessão global e experiências contrastantes [...] a ênfase passou a ser atribuída à melhoria da gestão econômica e liberação da força do mercado. Nos anos de 1990, o governo e as instituições passaram a ocupar o centro do debate, ao lado das questões de vulnerabilidade no âmbito local e nacional (BANCO MUNDIAL, 2002, p. 6).

Sua estratégia de redução da pobreza (extrema), anteriormente baseada na oferta de trabalho e de assistência social, é modificada na década de 2000. Agora, trata-se de "[...] promover oportunidades, facilitar a autonomia e aumentar a segurança dos pobres" 
(BANCO MUNDIAL, 2002, p. 6). O conceito de pobreza se amplia, passando a abranger outros fatores. De acordo com o documento de 2000/2001 (BANCO MUNDIAL, 2002, p. 12, grifo nosso): “[...] a estratégia apresentada neste relatório reconhece que a pobreza é mais do que renda ou desenvolvimento humano inadequado; como também vulnerabilidade, falta de voz, poder e representação"; incorporando, assim, uma visão multidimensional da pobreza, supostamente mais abrangente que a visão "econômica".

Ainda mais, no entendimento do Banco Mundial, os maiores responsáveis pelo malogro das suas iniciativas de combate à pobreza são os Estados nacionais. Os governantes dos países pobres seriam elitistas, ineficientes, corruptos, frágeis, incapacitados, como consta nos fragmentos a seguir (BANCO MUNDIAL, 2002):

Outra causa de vulnerabilidade é a incapacidade do Estado ou da comunidade em desenvolver mecanismos de redução ou alívio dos riscos que os pobres enfrentam (BANCO MUNDIAL, 2002, p. 37).

Em muitos casos, os governos são mais sensíveis aos interesses da elite do que às necessidades de segmentos pobres [...] (BANCO MUNDIAL, 2002, p. 39). A melhoria da administração pública também requer o reforço da capacidade administrativa e reguladora e a redução da corrupção. O ônus da corrupção em pequena escala recai desproporcionalmente sobre os pobres [...] (BANCO MUNDIAL, 2002, p. 39-40).

No mesmo relatório, o Banco Mundial faz referência ao documento Voice of the poors, elaborado em parceria com universidades, que representou uma tentativa de compreensão "[...] da realidade de mais de 60.000 homens e mulheres pobres de 60 países. Este estudo mostra que os pobres são agentes ativos em suas vidas, mas, em geral, não conseguem influenciar os fatores econômicos e sociais que determinam seu bem-estar" (BANCO MUNDIAL, 2002, p. 3). A pesquisa justifica o novo posicionamento da instituição diante da pobreza, redefinida em uma perspectiva multidimensional, sendo incorporados à análise aspectos ambientais e psicológicos. Neste contexto, afirmam, faz-se necessário "ouvir" diretamente aqueles que, há tempos, vivem quase sob as mesmas condições de penúria e se mostram "incapacitados" para romper com o círculo vicioso da miséria. 
A suposta "novidade" nesta estratégia é que o Estado já não será o agente fundamental na proteção das "populações pobres" ou de "risco social", mas as próprias comunidades vulneráveis mobilizarão seus recursos para reverter a situação, numa espécie de "empoderamenteo". Neste sentido, a nova concepção do Banco Mundial sobre os pobres, que "[...] agora devem ser vistos como administradores estratégicos de um portfólio complexo de ativos" (BANCO MUNDIAL, 2002), que a estratégia atual para combater a pobreza deve se orientar a "constatar e valorizar os recursos e capacidades que os pobres têm, em vez de insistir na escassez de ingresso ${ }^{2}$, como o enfoque da pobreza faz" (ARREGUI, WANDERLEY, 2009, p. 156).

Diante dos fatos, é possível constatar que a instituição modifica sua concepção de pobreza e as estratégias para combatê-la com o passar de uma década. Mesmo apesar de admitir a precariedade dos seus métodos anteriores, permanece a individualização da pobreza (ora como incapacidade do sujeito, ora como "vulnerabilidade" em relação ao contexto), a desarticulação da pobreza em relação à acumulação de riqueza, e a crença na força do comércio e na gestão capitalista como premissas da sua atuação programática para erradicar a pobreza. Outra publicação do Banco Mundial é o livro Globalização, crescimento e pobreza (BANCO MUNDIAL, 2003), em cujo prefácio se afirma que "[...] o foco da nossa pesquisa está no impacto da integração econômica sobre os países em desenvolvimento, em especial sobre a população pobre que vive nesses países" (BANCO MUNDIAL, 2003, p. 9). Nele, a instituição reitera que o fracasso das suas ações deve ser atribuído, em grande parte, a "[...] políticas econômicas incompetentes, bem como desemprego e nacionalismo exacerbado, [que] levaram os governos a adotar o protecionismo" (BANCO MUNDIAL, 2003, p. 33). Como consta na mesma fonte, para acentuar seu ideal de sucesso apresenta os Estados Unidos como exemplo de país desenvolvido e próspero: "[...] a maior e, em alguns aspectos, a mais bem-sucedida economia do planeta, oferecendo a milhões de pessoas pobres uma oportunidade de crescer e prosperar" (BANCO MUNDIAL, 2003, p. 33).

\footnotetext{
${ }^{2}$ Escassez de ingresso para os autores significa baixos ou inexistentes recursos financeiros.
} 
Incorporando o papel de "protetor" das nações pobres, o Banco Mundial sublinha, mais uma vez, que a ajuda internacional é o único meio destes países progredirem e se adaptarem à nova "realidade global":

Nações de baixa renda em processo de reforma têm dificuldade em atrair investimentos. Aqui a ajuda internacional pode ter um papel complementar de grande valor para auxiliar os países em processo de reforma de suas políticas com a esperança de se tornarem globalizados. Logo, umas das razões pelas quais a ajuda internacional aumenta o crescimento nos países com ambientes de boas políticas é que ela atrai investimentos (BANCO MUNDIAL, 2003, p. 98-99).

Com tal definição de pobreza o Banco Mundial pretende identificar, quantificar e qualificar os pobres. A partir das condicionalidades impostas pelo Banco Mundial aos países que demandam de apoio técnico e financeiro para receberem "ajuda" ou empréstimos, condiciona-se a política econômica desses países, colocando-os como reféns de suas normas e sua compreensão do que é melhor para o "desenvolvimento humano", para os trabalhadores e para as relações de produção, assim como indicam e fomentam instituições que estão direta ou indiretamente vinculadas aos interesses do poder hegemônico (organizações não governamentais, fundações, entre outras).

Sob a retórica de construir um mundo sem pobreza, o Banco Mundial, na verdade, a reforça, incentivando a acumulação da riqueza socialmente produzida. Seja pelos incentivos às dívidas públicas, ou seja, por apresentar soluções pontuais, com saídas temporárias das mais desumanas formas de vida, ou desenvolvimento econômico, tecnológico e científico sem distribuição igual do seu produto, o Banco Mundial demonstra seu lugar e sua opção política nessa sociedade, estruturada por interesses de classes antagônicos.

Em face do panorama global de pobreza e desigualdade, a comunidade internacional fixou várias metas para os primeiros anos do século, com base nos debates ocorridos em várias conferências das Nações Unidas realizadas nos anos 90, são elas (BANCO MUNDIAL, 2000, p. 6): reduzir pela metade a proporção de pessoas que vivem em situação de pobreza extrema (menos de 1 dólar por dia); assegurar educação primária universal; eliminar a desigualdade 
por sexo na educação primária e secundária (até 2005); reduzir em dois terços a mortalidade infantil; reduzir em três quartos a mortalidade materna; assegurar acesso universal a serviços de saúde reprodutiva; implementar estratégias nacionais de desenvolvimento sustentável em todos os países até 2005, para reverter a perda de recursos ambientais, a redução da pobreza e privação até 2015.

Diante de tantas metas, nos questionamos: serão possíveis tamanhas modificações nos índices humanos com um Estado ausente socialmente? Será possível solucionar a pobreza sem romper com o sistema que pressupõe a apropriação privada da riqueza socialmente produzida? Todas essas modificações seriam possíveis mediante ações de sustentabilidade social, empoderamento, dentre outras? A quem estaria atendendo os relatórios e as projeções do Banco Mundial, trabalhadores ou detentores dos meios de produção?

\subsection{Amartya Sen: o neodesenvolvimentismo, o microcrédito e o empoderamento}

O economista indiano Amartya Sen recebeu o Prêmio Nobel em 1998; seus trabalhos teóricos pretendem contribuir com uma nova compreensão dos conceitos sobre miséria, fome, pobreza e bem-estar social. Sobre o tema pobreza e miséria se destacam as obras Pobres e famintos: um ensaio sobre direito e privação, publicada em 1981, Desenvolvimento como liberdade, de publicação datada em 2000 e Desigualdade reexaminada, de 2001. Em suas obras o autor retoma princípios do liberalismo (propriedade privada, liberdade e igualdade de oportunidades para a livre concorrência no mercado).

A análise de seus trabalhos é um desafio importante, pois hoje a lógica de seu pensamento tornou-se uma referência para o Banco Mundial na proposta das políticas para os países periféricos e também foram incluídos indicadores sociais nos padrões de classificação dos países que resultou na criação do Índice de Desenvolvimento Humano (IDH).

Amartya Sen pensa a pobreza não sendo mensurável apenas pelo nível de renda (ou pobreza absoluta), mas como a privação de capacidades básicas que envolve acessos a bens e serviços; inclusive por isso lhe é atribuída a formulação de pobreza na sua multidimensionalidade. Para ele, o analfabetismo, a doença, a miséria, a falta de acesso ao crédito, a falta de acesso aos serviços públicos e a exclu- 
são da participação social e política, assim como outras, revelam-se como "privações de capacidades", que impedem a superação da pobreza (SEN, 2000). No entanto,

[...] a perspectiva da pobreza como privação de capacidades não envolve nenhuma negação da perspectiva sensata de que a renda baixa é claramente uma das causas principais da pobreza, pois a falta de renda pode ser uma razão primordial da privação de capacidades de uma pessoa (SEN, 2000, p.109).

A “questão social" e as suas expressões, para o autor, estão bem longe da discussão da acumulação capitalista e da apropriação privada da riqueza produzida. A concepção de desigualdade do autor vincula-se à desigualdade de oportunidades e da privação de necessidades básicas. A desigualdade é pensada individualmente, centrada no indivíduo e na ausência de condições básicas de sua existência (acesso à saúde, à educação, ao saneamento básico, à alimentação, etc.), únicos elementos capazes de serem proximamente igualados entre os indivíduos empiricamente tão diversos.

Para Sen, considerar as capacidades individuais básicas melhora o entendimento da natureza e das causas da pobreza e supera a concepção de resolução da pobreza como mera distribuição de renda, potencializando o alcance das liberdades. Quanto à "pobreza relativa", Sen entende que a privação relativa de rendas pode causar "pobreza absoluta" de capacidades. Ser relativamente pobre, num país rico, pode representar desvantagem de capacidade, mesmo se a renda absoluta for alta para os padrões mundiais. Assim, em países ricos, é necessário mais renda para obter o mesmo "funcionamento social". Sob esta ótica, o combate à pobreza faz-se mediante a ampliação das capacidades e expansão das liberdades.

A tese de Sen (2000), em Desenvolvimento como liberdade, é que o desenvolvimento representa um processo de expansão das liberdades reais que as pessoas desfrutam. Sendo assim, entende que as liberdades humanas contrastam com as análises restritas, em que o desenvolvimento é apresentado apenas como crescimento do produto, aumento das rendas pessoais, industrialização, avanço tecnológico ou modernização social. 
Partindo do pressuposto que o crescimento do Produto Nacional Bruto (PNB) e das rendas é um meio de expandir as liberdades, não um fim em si, a expansão da liberdade é considerada o fim primordial (tendo um papel constitutivo) e o principal meio do desenvolvimento (constituindo um papel instrumental). 0 papel constitutivo refere-se às liberdades substantivas, e, neste sentido, a utilidade da riqueza está nas liberdades substantivas que ela ajuda a obter. As liberdades substantivas incluem capacidades elementares, como ter condições de evitar privações (fome, subnutrição e morbidez evitável), bem como as liberdades associadas ao "saber-ter" participação política e liberdade de expressão. Para o autor, o desenvolvimento como liberdade não é apenas a eliminação das privações materiais, mas também das privações políticas e de direitos civis básicos, remontando, em sua análise, a proposição de Marshall discute sobre os direitos constitutivos da cidadania.

Assim, no pensamento de Sen, é possível identificar os seguintes aspectos centrais: a propriedade privada (SEN, 2001, p. 29); a igualdade (SEN, 2000, p. 52); a liberdade; o livre mercado; o individualismo e o desenvolvimento, o qual nos ateremos em nossa discussão.

\section{- Desenvolvimento}

Para Sen (2000, p.10) "[...] o desenvolvimento seria baseado, não apenas no crescimento econômico, mas na eliminação das privações de liberdade e na criação de oportunidades [...]", que podem ser desfrutadas no mercado de forma contínua. O livre mercado é a aposta como agente principal do desenvolvimento, as oportunidades surgem naturalmente dado o conjunto de liberdades básicas.

Assim, a eliminação da pobreza, tida como um "acoplamento de desvantagens" que reduzem o potencial humano e priva-o de suas capacidades, pode ser alcançada com a criação de um círculo virtuoso que quebre esse acoplamento de desvantagens (SEN, 2000, p. 113). "Quanto mais incluso for o alcance da educação básica e dos serviços de saúde, maior será a probabilidade de que mesmo os potencialmente pobres tenham uma chance maior de superar a penúria" (SEN, 2000, p. 113). 
Essa é a fórmula para o rompimento com o "ciclo da pobreza", e o resultado é "certamente" o desenvolvimento econômico, o que permitiria às pessoas levar a vida da forma que melhor julgarem. $\mathrm{O}$ autor complementa:

[...] muito além da observação do fato de a pobreza ser uma enorme tragédia que arruína a vida de expressivo número de pessoas em todo o mundo. A imensa tragédia da pobreza é, em si, suficientemente óbvia: vidas exauridas, felicidades sufocadas, criatividade destruída, liberdades erradicadas pelos infortúnios da pobreza.

A visão clássica de que a pobreza se resume à escassez de renda talvez já esteja fixada em nossas mentes, mas, em última análise, deve ser encarada como falta de liberdade de diversos para que se usufruam condições de vida minimamente satisfatórias. A baixa renda certamente contribui para essa situação, somada à influência de diversos outros fatores, como a falta de escolas, de equipamento de saúde e de medicamentos, subjugação da mulher, problemas ambientais, falta de empregos (o que afeta os indivíduos mais do que a renda). A pobreza pode ser reduzida mediante a aplicação de benefícios sociais, mas para garantir isso, é necessário empoderar as pessoas, principalmente as mais afetadas pela miséria, para que bens e serviços sejam aplicados de modo efetivo e as deficiências sejam eliminadas. [...] Os indivíduos permanecem desempoderados em decorrência de diversos processos complexos (SEN, 2009, p. 25).

A ideia é que o próprio movimento do indivíduo, a partir do aproveitamento de oportunidades existentes ou criadas por ele mesmo, gera o desenvolvimento. É como se cada um pudesse ou tivesse, quando livre de privações, possibilidade de criar ou desenvolver um negócio para si e pudesse, se assim desejar, tornar-se um empresário, ou no mínimo, um empresário de si mesmo, escolhendo o melhor trabalho que serve às suas características pessoais, podendo ser filósofo ou carregador (Smith apud SEN, 2009) como desejar.

O autor argumenta que a resolução de problemas sociais como a pobreza e a mortalidade, pode ser obtida por dois tipos de processos distintos: os processos mediados pelo crescimento e aqueles 
mediados pelo custeio público. No primeiro tipo de processo, a solução é desencadeada pelo crescimento econômico rápido, devendo ter uma base ampla e ser economicamente abrangente. Neste caso, seria importante ter uma forte orientação para o emprego e utilizar a prosperidade para a expansão de serviços sociais relevantes, como saúde, educação e segurança social.

O processo mediado pelo custeio público não é incompatível com países pobres. A solução estaria nos preços e custos relativamente baixos, importantes para determinar o quanto um país pode gastar. A viabilidade do processo deve-se ao fato de os serviços sociais relevantes serem altamente trabalho-intensivo, barato, devido aos baixos salários nos países pobres. "Uma economia pode ter menos dinheiro para despender em serviços de saúde e educação, mas também precisa gastar menos dinheiro para fornecer os mesmos serviços, que nos países mais ricos custariam muito mais" (SEN, 2000, p. 65). O autor lembra que há interesse em dar ênfase a essas disposições sociais sem esperar primeiro se transformar num país rico, uma vez que educação e os serviços de saúde são também imprescindíveis para o crescimento.

Amartya Sen (2000) sustenta a importância de pensar a pobreza com outros fatores que não se reduzam à renda, derivando no uso do conceito multidimensional da pobreza. Contudo, sua análise sobre a pobreza negligencia a dinâmica da acumulação do capital além de reatualizar a Teoria do "Capital Humano", a Naturalização dos problemas sociais, entre outros temas. Como propostas de resolução da pobreza, o autor aponta: o microcrédito, como aposta no desenvolvimento e no empoderamento.

\section{- O combate à pobreza: papel do microcrédito para o desenvolvimento}

Para Sen (2000), o desenvolvimento, como liberdade, e esta como realização das pessoas, conta com um instrumento privilegiado para ser atingido: o microcrédito.

Este consiste em pequenos créditos, de forma flexível, desburocratizada e com juros baixos, para as populações mais carentes, como forma de permitir o financiamento a atividades produtivas, educativas e outras, que os créditos comuns não permitem. O microcrédito permitiria às famílias e aos indivíduos a geração de fon- 
tes de renda, a construção de moradias, o acesso à escola etc., promovendo-se, assim, a realização das pessoas, ou seja, a liberdade, fundamento do desenvolvimento, na concepção do autor.

Neste sentido, ao promover o microcrédito como instrumento fundamental do desenvolvimento, da liberdade, e, portanto, das formas de combate à pobreza, o pensamento de Sen se articula com as formulações e ações de outro indiano: Muhammad Yunus, conhecido como o "banqueiro dos pobres".

Economista, nascido em Bangladesh em 1940, Yunus cria, em 1983, o Grameen Bank ou "Banco dos Pobres" (que já existia como instituição de crédito desde 1976), outorgando "microcrédito" para milhões de pessoas pobres, o que lhe valeu o Prêmio Nobel da Paz, em 2006. Assim, ele leva à prática os postulados teóricos de Sen: combater a pobreza, criando oportunidades às famílias pobres mediante o acesso a microcrédito, este tido como um "direito humano", que tem por objetivo criar fonte de renda às famílias pobres.

Mas o microcrédito não apenas se orienta para questões econômicas. Para Yunus, "[...] o microcrédito não se limita a libertar da fome os pobres; ele também contribui para sua emancipação política. [...]. O microcrédito pode não ser uma solução, mas é uma força de mudança, não só econômica e pessoal, mas também social e política" (YUNUS; JOLIS, 2001, p. 9-10).

Ele é apresentado, então, não só como forma de enfrentamento da pobreza econômica, mas como forma de propiciar melhorias políticas, culturais e sociais. Isso sem alterar os fundamentos estruturais da sociedade capitalista, que gera a desigualdade como resultado da sua contradição central, entre capital e trabalho: a exploração de uma classe por outra.

Assim, o combate à pobreza, em particular, se faz a partir da própria atividade financeira, que facilita o crédito a regiões, famílias e pessoas que os bancos comuns não atendem. Este processo se torna tão estratégico para o capital que, além dos Nobéis de Economia (Sen, em 1998) e da Paz (Yunus, em 2006), a ONU proclama 2005 como o Ano Internacional do Microcrédito. O microcrédito tem se tornado uma realidade promovida por quase todos os governos que rezam na cartilha das reformas neoliberais: a promo- 
ção de microempresas, o estímulo às cooperativas e os programas de Economia Solidária, que contam com cursos de capacitação, e acesso a créditos e microcréditos.

\section{- Combate à pobreza: a proposta do Empoderamento}

Para o autor, a pobreza é representada pelo fracasso dos sujeitos no mercado, reforçado ainda pela baixa autoestima, pela apatia e pelo desempoderamento, na medida em que:

Os fracassados e os oprimidos acabam por perder a coragem de desejar coisas que outros, mais favoravelmente tratados pela sociedade, desejam confiantemente. A ausência de desejo por coisas além dos meios de que uma pessoa dispõe pode refletir não uma valoração deficiente por parte dela, mas apenas uma ausência de esperança, e o medo da inevitável frustração. O fracassado enfrenta as desigualdades sociais ajustando seus desejos às suas possibilidades (SEN, 1990, p. 10-11).

Como estratégia de combate à pobreza, Amartya Sen propõe um modelo de desenvolvimento que permita a expansão das liberdades substantivas e instrumentais das pessoas: esse é um projeto (de sociedade) considerado em aberto, não definido (como seria o projeto socialista), orientado para as pessoas enquanto agentes, respeitando a diversidade humana e a liberdade de escolha. A pobreza e a tirania são os principais entraves à liberdade, segundo o autor. O empoderamento dessas pessoas é, então, proposto como meio e fim para a "transformação das relações de poder existentes" e superação do estado de pobreza. As estratégias de combate à pobreza se inserem, então, num processo essencialmente político, que precisa de atores capazes de "alterar correlações de força" em níveis macro, meso e micro articulados em torno de temas e lutas comuns, o que, para Sen, se traduz em empoderamento dos pobres, se orienta para a conquista da cidadania, enquanto plena capacidade de um ator (individual ou coletivo) de usar seus recursos econômicos, sociais, políticos e culturais para atuar com responsabilidade no espaço público na defesa de seus direitos, influenciando as ações dos governos na distribuição dos serviços e recursos. Neste sentido, os processos de transformação do Estado e de mudança social assentam na 
construção de redes e amplas alianças dos movimentos sociais e das organizações populares no campo da sociedade civil.

Assim, a abordagem de empoderamento implicaria no desenvolvimento das capacidades individuais dos pobres e excluídos e de suas organizações, o que seria suficiente para transformar as relações de poder, que limitam o acesso a bens, e as relações em geral com o Estado, o mercado e a sociedade civil. Por meio do empoderamento ter-se-ia a expectativa de que essas pessoas pobres e excluídas superariam as principais fontes de privação das liberdades, poderiam construir e escolher novas opções e poderiam implementar suas escolhas e se beneficiar delas.

As capacidades individuais representam, portanto, para Sen (2001), graus de poder (do pobre, do excluído) para fazer ou deixar de fazer coisas. Assim, o conceito de capacidades não significaria só as habilidades das pessoas, mas também as oportunidades reais que essas pessoas têm de fazer o que querem fazer (SEN, 2001).

Para o autor, o empoderamento é um dos vários conceitos tratados para tal desenvolvimento, conjuntamente com a participação, a descentralização, o capital social etc. Este debate tem sido proposto, nos últimos tempos, tanto pelos defensores de uma globalização regida pelo mercado (ou, dito de outra forma, pelo Império, pelo Consenso de Washington, pelo neoliberalismo) quanto pelos que defendem a construção de um outro mundo possível, neoliberais e pós-modernos confluem nesses projetos: os primeiros com o objetivo de dominar e ampliar a acumulação, os segundos visando humanizar o capital e incluir o excluído.

Sen propõe, assim, o empoderamento como um projeto alternativo que implica na promoção de um modelo de desenvolvimento que permita a expansão das liberdades substantivas e instrumentais das pessoas. Ou seja, um projeto (de sociedade) em aberto, orientado para as pessoas enquanto agentes e que respeita a diversidade humana e a liberdade de escolha. Nesse projeto a pobreza e a tirania são os principais entraves a serem enfrentados.

Assim, as estratégias de combateà pobrezainscrevem-se num processo essencialmente político, que precisa de atores capazes de alterar correlações de força nos diversos níveis sociais e articulados em tor- 
no de temas e lutas comuns. Atores com poder diferentes são necessários como catalisadores no processo de empoderamento. Ao mesmo tempo, as características desses processos, suas potencialidades e limites, são diversas em função do tipo de mediadores; por exemplo: movimentos sociais, Organizações não Governamentais (ONGs), governos, agências multilaterais que atuam como catalisadores.

No combate à pobreza, para Sen, o empoderamento dos pobres e de suas organizações se orienta para a conquista da cidadania, isto é, a conquista da plena capacidade de um ator individual ou coletivo de usar seus recursos econômicos, sociais, políticos e culturais para atuar com responsabilidade no espaço público na defesa de seus direitos, influenciando as ações dos governos na distribuição dos serviços e recursos.

Por fim, chama a atenção que Sen conceba um projeto que transformaria as "relações de poder" e a "correlação de forças" mediante o suposto “empoderamento" dos pobres sem, porém, imaginar qualquer alteração nos fundamentos estruturais do poder econômico e político: a propriedade privada dos meios de produzir riqueza, a exploração da força de trabalho, o enorme poder concentrado nos monopólios, nas instituições como o Fundo Monetário Internacional (FMI) etc. Parece que o "empoderamento dos pobres e subalternos" não precisaria de um "des-empoderamento dos ricos e poderosos". Este parece ser mais um projeto ideológico do que um processo que efetivamente altera a correção de forças sociais.

Chama também a atenção a concepção do autor de um projeto social aberto (descartando e rejeitando projetos fechados, como os projetos socialista ou comunista). Qual seria essa sociedade? Um capitalismo mais humanizado estaria dentro do horizonte propositivo de Sen? Este parece ser mais um debate sem conteúdo específico, que gera adesões a partir da livre interpretação que cada um faz da (vazia) proposta do autor.

\section{POBREZA, DESENVOLVIMENTO E DESIGUALDADE}

\subsection{Acumulação e pauperização na Lei Geral da Acumulação Ca- pitalista}

Para compreender a abordagem marxiana sobre a pobreza e pensarmos suas formas de enfrentamento, partimos de alguns pres- 
supostos: a pobreza só pode ser explicada na sociedade capitalista em relação à contradição de classes, e para compreender as formas de enfrentamento às expressões da chamada "questão social" é necessário conhecer as determinações impostas historicamente pelas contradições próprias do modo de produção capitalista e pela luta de classes. Tais determinações constituem a realidade concreta na qual os sujeitos históricos se movem. A dimensão econômico-política das formas de enfrentamento do Estado/Sociedade Civil ocorre no contexto da acumulação capitalista, marcada, atualmente, pela hegemonia do capital financeiro.

\section{a) A pobreza não é um fenômeno por si só explicável}

A pobreza, no Modo de Produção Capitalista (MPC), não pode ser lida como um fenômeno isolado, distante da relação social posta por esta sociedade (que se mantém sob os pilares da contradição de classes, uma relação entre aqueles que vendem a sua própria força de trabalho e aqueles que a compram).

A pobreza não é um resquício de sociedades pré-capitalistas, ou um produto de um insuficiente desenvolvimento. Ela é um produto necessário do MPC. O capitalismo, como sistema social de produção de valores, tem como resultado do seu próprio desenvolvimento a acumulação de capital por um lado, e a pauperização absoluta e relativa por outro (MARX, 1980, p.712).

Desta forma, o próprio desenvolvimento capitalista, o aumento da riqueza socialmente produzida, não só não reduz a pobreza, como, pelo contrário, a produz e amplia: com mais desenvolvimento capitalista, maior pauperização (MONTAÑO, 2012). A maior riqueza produzida na sociedade comandada pelo capital não gera sua maior distribuição, mas sua acumulação. Quanto maior a riqueza socialmente produzida, maior a acumulação dela por alguns poucos (que dela se apropriam mediante a exploração de mais-valia) e maior a pauperização da maioria (que a produzem, mas pouco lhes resta em relação à riqueza por eles produzida).

Assim, pobreza não é um aspecto residual, transitório do capitalismo, é estrutural e resultado do seu próprio desenvolvimento. $\mathrm{O}$ capitalismo gera acumulação, por um lado, e pobreza, por outro; jamais eliminará um ou outro. 


\section{b) A População pauperizada não é marginal, e sim necessária}

Essa é uma discussão tão polêmica quanto necessária. Em contexto de análises individualizantes, guiadas ou pela tradicional racionalidade positivista ou pela emergente racionalidade pós-moderna, as análises microssociais sem mediações com a totalidade esbarram no binômio integrado/marginal, funcional/disfuncional, ou incluído/ excluído; e categorias tão fundamentais como: exploração, contradição, luta de classes, entre outras, saem de cena. Retomando Marx (1980), o excedente populacional não é marginal, mas necessário e funcional ao capital, apresentando as seguintes funções: 1) Oferta de material humano a serviço das necessidades variáveis de expansão do capital; e 2) Regulação dos salários, e direitos trabalhistas.

A existência do Exército Industrial de Reserva (EIR) está diretamente vinculada à acumulação de riqueza pelo capitalista, ou seja, quanto maior a potência de acumular riqueza, maior tende a ser a magnitude do EIR. E quanto maior esse EIR em relação ao exército ativo, tanto mais tende a crescer a superpopulação. E quanto maior a massa de superpopulação, maior o pauperismo.

A lei de acumulação na sociedade capitalista se estabelece: com o crescimento dos meios de produção há uma diminuição do dispêndio da força humana, assim não é o trabalhador que emprega os meios de produção, mas o contrário, quanto maior o desenvolvimento dos meios de produção maior a pressão sobre o trabalhador e maior a sua exploração, que tende a aumentar a autovalorização do capital; a classe trabalhadora hoje cresce mais rápido do que as necessidades do capital, o que tende a ampliar o EIR; embora, no plano da aparência, o trabalho humano pareça supérfluo, mas é fundamental para o capital, por isso a necessidade de ter em abundância força de trabalho disponível sujeita a desempenhar qualquer atividade, em qualquer circunstância; a acumulação de miséria equivale à acumulação de capital; e, por fim, na medida em que se acumula o capital tendem a piorar as condições de trabalho, mesmo mediante o aumento do salário.

\section{c) "Pauperização absoluta" e "pauperização relativa"}

Ainda que, muitas vezes, a diferenciação entre a pauperização absoluta e relativa assuma a aparência esquemática e meramente 
conceitual, no contexto atual, se torna fundamental a sua explicitação, inclusive para compreender as formas de seu enfrentamento.

Conforme Marx analisa, é uma lei geral da acumulação capitalista a substituição paulatina e permanente de força de trabalho (capital variável) por maquinaria e meios de produção (capital constante) (MARX, 1980, p. 224). Como resultado disso, segundo já apontamos, o próprio desenvolvimento das forças produtivas, comandado pela lógica e interesses hegemônicos do capital que torna a força de trabalho, e o operário, um mero apêndice, extensão da máquina-ferramenta (MARX, 1980, p. 482) e que leva à subsunção real do trabalho ao capital (MARX, 1980, p.92-93, 104108) expulsa cada vez maior volume de trabalhadores do mercado formal de trabalho. Sendo a única fonte de renda do trabalhador a venda da sua força de trabalho, a impossibilidade deste ser empregado pelo capital o leva a um processo de empobrecimento ou pauperização absolutos.

- Pauperização absoluta. É nesse processo, tendencialmente permanente e ineliminável no desenvolvimento capitalista, que se constitui e se expande a pauperização absoluta. Para Marx (1980), pauperização ou pobreza absoluta é o resultado, cada vez mais expandido e atingindo cada vez maior volume da população trabalhadora, do próprio desenvolvimento das forças produtivas, da própria expansão capitalista, em que o trabalhador é constantemente expulso do mercado de trabalho, não tendo, assim, qualquer possibilidade de sustentação mediante a venda da sua força de trabalho. O trabalhador sem emprego é um trabalhador sem salário, portanto, sem fonte de renda.

O desemprego é, portanto, um processo estrutural, tendencial do sistema capitalista, jamais relacionado à precária condição subjetiva do trabalhador. O desemprego não é, na análise de Marx, resultado das carências pessoais do indivíduo, mas das próprias condições estruturais do desenvolvimento capitalista. Assim, qualquer proposta de "combate ao desemprego" mediante programas de qualificação, de auto-ajuda, de microcrédito etc., no entanto, não o supõem como resultado estrutural do capitalismo, mas como déficit do trabalhador, é considerado, nesta perspectiva, um paliativo individual que em nada altera os fundamentos ou o efeito geral do 
problema: o desemprego e a pauperização absoluta. Não é, por exemplo, a qualificação deste ou daquele desempregado que vai ajudar a resolver o problema do desemprego em geral.

Segundo a Comissão Econômica para a América Latina (Cepal), um terço da população da América Latina vive com menos de dois dólares por dia. São 185 milhões de pessoas, só o Brasil contribui com 49 milhões dessa soma, estando entre as maiores economias do mundo (CACCIA BAVA, 2011).

Mas a pauperização absoluta não se conforma apenas pelos desempregados. Como um dos efeitos do EIR, como já observamos, há uma tendencial queda do salário, por debaixo do valor da força de trabalho, tendo o trabalhador uma remuneração insuficiente para sua sobrevivência. No atual contexto de crise e reestruturação neoliberal do capital, as mudanças nas relações capital-trabalho, a precarização nos direitos trabalhistas, nas conquistas do trabalhador de direitos sociais, a terceirização ou subcontratação etc., levam a que o próprio trabalhador assalariado, com salários tão baixos, sofra um processo de pauperização absoluta. Prova disso é a crescente massa de trabalhadores que vive em condições de carências de algumas das necessidades fundamentais, abaixo do nível de subsistência.

- Pauperização relativa. Pode ser caracterizada, a pauperização relativa, como o processo de progressivo aumento da distância entre o valor produzido pelo trabalhador e a parcela dessa riqueza produzida da qual este se apropria. Ou seja, a riqueza produzida pelo trabalhador se divide numa parte cada vez maior de mais-valia (apropriada pelo capital), e outra parte, proporcionalmente cada vez menor, que corresponde ao seu salário (parte da riqueza produzida que fica com o trabalhador).

Assim sendo, mesmo podendo algum trabalhador ter um salário que lhe permita condições boas ou ótimas de vida (elevado poder aquisitivo), a parte de valor por ele produzido que permanece com ele é cada vez menor em relação ao total da riqueza produzida (ou da mais-valia pelo capitalista apropriada). Por ser inerente e fundamental à sociedade capitalista, a pobreza é ineliminável. Portanto, ao crescer a riqueza amplia-se necessariamente a pobreza, mesmo em países que possuam o índice de miséria e indigência 
próximo de, ou igual, a zero, e mesmo em locais ou cidades onde os trabalhadores vivam com conforto e suas necessidades básicas integralmente satisfeitas, suas aquisições são, em relação à riqueza produzida e acumulada, inferiores.

Os planos de findar a miséria, portanto pobreza absoluta, pode ser compatível com a sociedade capitalista, mas a pobreza relativa sempre existirá nessa sociedade.

\section{d) Pobreza, a outra face da acumulação capitalista}

É a partir das considerações anteriores que podemos concluir sobre o papel central que a pobreza tem no pensamento marxista. Tal centralidade sustenta-se no fato dela ser, não um processo deflagrado pelas carências individuais ou até de um determinado grupo ou região, mas uma determinação estrutural do próprio Modo de Produção Capitalista.

A pobreza, nesta perspectiva, não é o resultado do insuficiente desenvolvimento capitalista, nem é o efeito marginal de uma fase de crise. No capitalismo, a pobreza é um produto estrutural de seu desenvolvimento. É que o desenvolvimento capitalista, o aumento da riqueza socialmente produzida, não deriva em maior distribuição, mas em maior acumulação de capital. No capitalismo, a maior riqueza produzida significa maior apropriação privada, e não maior socialização dessa. A acumulação de riqueza, por um lado, é complementada pela pauperização (absoluta ou relativa) por outro.

\subsection{Pobreza e acumulação no debate profissional}

Em concordância com a perspectiva que aqui assumimos, desenvolve-se, na profissão, uma análise sobre a pobreza que não apenas a apresenta como parte de uma relação de desigualdade (e não como um processo autônomo), como um produto social (e não natural), mas também como um fenômeno fundado nas determinações que, no MPC, se expressam e derivam da Lei Geral da Acumulação Capitalista, enfrentando num mesmo processo a pobreza e a acumulação de capital.

No Serviço Social brasileiro, Marilda lamamoto inaugura o estudo dos fundamentos da profissão embasada na análise da obra marxiana, particularmente n'O Capital. O texto, Relações sociais e Serviço Social, publicado em 1982, em coautoria, é resultado da sua dissertação 
de mestrado, envolvida em pesquisa promovida pelo Centro de Estudos Latino-americano de Trabalho Social (CELATS) sobre a História do Trabalho Social na América Latina. Dez anos depois, com o título de Renovação e conservadorismo no Serviço Social, a autora publica um livro constituído com capítulos inéditos da sua dissertação e outros ensaios de conferências (IAMAMOTO, 1992).

Neles, lamamoto (1992) questiona as abordagens neoconservadoras que promovem uma "psicologização das relações sociais", numa concepção que individualiza a compreensão dos problemas sociais - cujos fundamentos econômicos e suas expressões materiais e objetivas são negligenciados ou equalizados às dimensões existenciais e subjetivas -, e do seu enfrentamento. Nos termos da autora, esta visão

[...] privilegia [os] problemas de desintegração e desadaptação social e funcional [...]. Esta ênfase leva a dar prioridade às necessidades que transcendem as carências objetivas e materiais do cliente, isto é, os problemas existenciais [...]. As exigências de sobrevivência são tidas como demandas secundárias para uma profissão que procura ultrapassar o estigma assistencialista. Os problemas materiais tendem a ser espiritualizados, transformados em dificuldades subjetivas, de adaptação social [...] (IAMAMOTO, 1992, p. 34, grifo nosso).

Com tal psicologização dos problemas, as carências materiais são relegadas em face das questões subjetivas e culturais, lamamoto questiona a concepção (neotomista) do sujeito, como "pessoa humana”, quando, no afã de apresentá-lo na sua diversidade, na sua heterogeneidade, acaba sendo deslocado da sua condição de classe. Assim, para a autora, nesta perspectiva defende-se que

[...] o cliente não deve ser visto como um "pobre", mas como uma "pessoa": todos os cidadãos são clientes potenciais do Serviço Social, visto que todos podem apresentar problemas relacionais e afetivos que precisam de orientação psicossocial. Instaura-se, assim, uma tendência transclassista na consideração da clientela do Serviço Social, em choque com sua realidade efetiva, constituída dos segmentos mais pauperizados da classe trabalhadora (IAMAMOTO, 1992, p.34). 
Quando a clara e crítica conceituação do sujeito passível de intervenção profissional (o trabalhador, o "pobre", na sua relação com o capital, com a acumulação e com a exploração) e sua problemática (desdobramentos ou manifestações da "questão social", como a contradição capital-trabalho) são substituídos pelas (ou equalizados às) noções de "povo”, “cidadão”, “subalterno”, “carente”, não diferenciando o que é fundamento do que é manifestação, o que é causa do que é consequência, tende-se a perder a compreensão crítica do real papel profissional, identificando-o com a mera intencionalidade do profissional, desenvolvendo a crença de que, com tais intenções, sempre e naturalmente, o assistente social na sua intervenção, beneficia o usuário. Assim, conforme a autora, mesmo que

[...] mobilizado por motivações pessoais e pela "boa intenção" de solidariedade humana aos setores mais pauperizados e oprimidos da sociedade, o profissional acredita, frequentemente, estar trabalhando para os interesses do "povo". Porém, sua crença é subvertida através de sua prática, transmutando-se em resultados que negam as representações de seu fazer. Confunde, frequentemente, intenções com o resultado e o significado social de sua intervenção profissional na sociedade (IAMAMOTO, 1992, p.53).

É nesse sentido que lamamoto problematiza o "papel pedagógico" por ela defendido para o Serviço Social. Para lamamoto, tal "pedagogia emancipatória”, que vincula o profissional como "intelectual orgânico" às "classes subalternas”, num projeto revolucionário, reatualiza a indistinção da prática profissional e a ação militante, não diferenciando o assistente social "enquanto profissional assalariado" e "enquanto cidadão político". Esta confusão não permite ver que o Serviço Social constitui "uma especialização do trabalho na sociedade, e não uma atividade que se inscreva na arena da política stricto sensu (IAMAMOTO; CARVALHO, 2007, p. 323). Assim, no defendido "compromisso profissional com as lutas das classes subalternas", como aparece em Abreu e outros, parece defender-se um "Serviço Social socialista", algo difícil de conceber para "uma profissão exercida predominantemente na esfera do Estado burguês, nas corporações empresariais e nas chamadas 'organizações da sociedade civil”' (IAMAMOTO; CARVALHO, 2007, p. 325-6). 
Num caminho semelhante, agora tratando da "tese da assistência social”, presente particularmente na obra de Yazbek (1996), quando "[...] a população alvo das políticas de assistência social [...] é lida a partir da categoria de 'subalterno"' (IAMAMOTO; CARVALHO, 2007, p. 306), lamamoto questiona a noção de "exclusão integrativa" e o conceito de "subalternidade", por serem desenvolvidos sem a consideração dos fundamentos do MPC. Para lamamoto e Carvalho (2007, p. 307), “[...] a noção de 'exclusão integrativa' não envolveu o enfrentamento teórico da lei geral da acumulação e sua correspondente lei da reprodução da população que lhe atribuem inteligibilidade", o que leva Yazbek (1996) a trabalhar com a relação "pobreza/assistência" e não "trabalho/assistência". Ao interpretar a "pobreza" como subalternidade e não como uma manifestação da relação capital-trabalho, acaba-se dissociando o pobre do trabaIhador, e a pobreza dos fundamentos da relação capital-trabalho ou pobreza/acumulação.

É com estas críticas que lamamoto analisa os fundamentos do capitalismo e desvenda a gênese e o papel social do serviço social, sustentado-se na obra de Marx. Procurando na Lei Geral da Acumulação Capitalista, Iamamoto compreende a relação do desenvolvimento das forças produtivas (comandadas pelo capital) com a constituição de um excedente populacional e com o salário do trabalhador; tendo a queda tendencial do salário e o aumento tendencial do excedente populacional como fatores centrais no processo de pauperização absoluta e relativa. Para lamamoto e Carvalho,

[...] o desenvolvimento das forças produtivas sociais do trabalho permite ao capitalista, com o mesmo desembolso de capital variável [com o mesmo gasto com força de trabalho] colocar em ação maior quantidade de trabalho, mediante maior exploração intensiva e extensiva de força de trabalho individuais. Esse excesso de trabalho de trabalhadores ativos tem como contrapartida o engrossamento das filas de trabalhadores em reserva, ao mesmo tempo em que a pressão deste sobre aqueles obriga-os a trabalharem mais e a se submeterem às pressões do capital [...]. O movimento geral de salários passa a ser regulado, em termos gerais, pelas expansões e contrações da população trabalhadora sobrante (IAMAMOTO; CARVALHO, 1995, p. 60). 
Seguindo Marx na caracterização das modalidades do EIR, lamamoto caracteriza o pauperismo (absoluto) como uma modalidade do EIR, ou seja, da classe trabalhadora, expulsa do mercado de trabalho ou com salários de miséria, e, portanto, a pobreza absoluta causada e determinada pelos fundamentos da Lei Geral da Acumulação Capitalista. Neste sentido, o pauperismo (absoluto) constitui uma camada social dos trabalhadores: órfãos e filhos de pobres, vítimas da grande indústria: viúvas, mutilados, doentes (IAMAMOTO; CARVALHO, 1995, p. 61-62).

A pauperização é, para a autora, como para Marx (1980), resultado do processo de desenvolvimento das forças produtivas, e, dialeticamente, atrelada ao processo de acumulação de capital. Afirma lamamoto e Carvalho (1995, p.62): “[...] quanto maior é o crescimento econômico, isto é, a acumulação, maior também é o contingente absoluto do proletariado e a capacidade produtiva de seu trabalho; e tanto maior é o exército industrial de reserva. Este cresce ao crescer a riqueza social".

E este processo não é algo fortuito, externo à própria lógica do capital, mas estrutural e próprio da sua dinâmica, pois "[...] o capital mantém sempre a superpopulação relativa em proporção às suas necessidades de acumulação" (IAMAMOTO; CARVALHO 1995, p. 61-62). Para lamamoto, portanto, pobreza e riqueza, pauperização e acumulação, se desenvolvem simultânea e articuladamente, pois "a acumulação da miséria é proporcional à acumulação do capital" (IAMAMOTO; CARVALHO, 1995), ou “[...] o enriquecimento do capitalista tem sua outra face: o empobrecimento do trabalhador (IAMAMOTO, 1992, p. 64).

Em síntese, conforme a autora,

[...] a lei geral da acumulação supõe a acumulação da riqueza [...] inseparável da acumulação da miséria e da pauperização daqueles que produzem a riqueza [...]. A reprodução ampliada do capital supõe a recriação ampliada da classe trabalhadora e do poder da classe capitalista e, portanto, uma reprodução ampliada da pobreza e da riqueza e do antagonismo de interesses que permeia tais relações de classes, o qual se expressa na luta de classes (IAMAMOTO; CARVALHO 1995, p. 66). 
É neste processo, de aumento da pobreza (nas suas diversas manifestações) e da acumulação de capital a partir do desenvolvimento das forças produtivas, e de lutas de classes, que surgem e se expandem as políticas sociais estatais, como forma de promover a acumulação e diminuir a conflitividade social, e como resultado das lutas de classes (IAMAMOTO; CARVALHO, 1995, p.7779). Assim, afirma a autora que,

\begin{abstract}
[...] face ao crescente processo de expropriação a que estão submetidos os trabalhadores no movimento de expansão do capital, sua pauperização tende a aumentar em relação ao crescimento acelerado do capital. Diante dessa lei da acumulação, o Estado, em seu "papel de árbitro das relações de classe", assume tarefas cada vez mais ativas no sentido de zelar pela reprodução da força de trabalho, não só através de legislação específica [...] como através da prestação de serviços básicos (IAMAMOTO; CARVALHO, 1995, p. 100).
\end{abstract}

Essas formas de intervenção estatal são, para o capital, mecanismos de garantia da acumulação capitalista e legitimação da ordem (IAMAMOTO; CARVALHO 1995, p. 101-102), enquanto, para o trabalhador, elas significam e representam serviços que, mesmo que insuficientes, permitem a satisfação de certas necessidades (IAMAMOTO; CARVALHO 1995, p. 103).

Outro exímio intelectual desta perspectiva, José Paulo Netto (2007), trata expressamente da Desigualdade, Pobreza e Serviço Social na abertura da $33^{a}$ Conferência Mundial de Escolas de Serviço Social, organizada pela IASSW, em Santiago do Chile, em 2006.

No seu texto (NETTO, 2007), o autor, após apresentar o quadro quantitativo da pobreza, na América Latina e no mundo, e seu aprofundamento nas últimas décadas de transformações neoliberais, caracteriza a pobreza como um pólo de uma relação de desigualdade, tendo a riqueza (e a acumulação capitalista) no outro pólo dessa: “[...] a produção capitalista é simultaneamente produção polarizadora de riqueza e de pobreza (absoluta e relativa)" (NETTO, 2007, p. 143). Tal desigualdade, afirma, é um “[...] fenômeno recorrente, embora com padrões bastante diferenciados, no conjunto das sociedades capitalistas" (NETTO, 2007, p. 140). 
O autor conceitua, portanto, a pobreza (particularmente a relativa) e a desigualdade como fenômenos atrelados ao desenvolvimento das forças produtivas, que se funda na Lei Geral da Acumulação Capitalista. Segundo ele, "[...] pobreza relativa e desigualdades são constitutivos insuperáveis da ordem do capital - o que pode variar são seus níveis e padrões" (NETTO, 2007, p. 159). Ou seja, para o autor, ao pensar o crescimento econômico, a pobreza e a desigualdade, na perspectiva marxista, constata-se que "[...] desenvolvimento capitalista é, necessária e irredutivelmente, produção exponenciada de riqueza e produção reiterada de pobreza [...]”, sendo isto um “[...] traço, que é próprio da dinâmica do desenvolvimento capitalista - e que encontra a sua fundamentação teórica nos desdobramentos da lei geral da acumulação capitalista" (NETTO, 2007, p. 142).

Assim sendo, não é o desenvolvimento ou crescimento capitalista que reduz a pobreza, mas este desenvolvimento tende a ampliá-la; neste sentido, o autor afirma que "[...] é falsa a tese segundo a qual o crescimento econômico é a única condição necessária para enfrentar, combater e reduzir o pauperismo que decorre da acumulação capitalista (e, na mesma medida, para reduzir desigualdades)" (NETTO, 2007, p. 143). Desenvolvimento econômico e aumento da pobreza são fenômenos estruturalmente ligados e relacionados no capitalismo. Tal crescimento poderá reduzir a pobreza só quando ocorrerem certas condições: quando este for longo e expressivo; quando for acompanhado de uma política redistributiva [resultado, claro, de conquistas e lutas de classes]; e num quadro de baixa inflação (NETTO, 2007, p. 144).

O autor, ainda, considera as profundas mudanças operadas desde a formulação marxiana dessa "lei geral", e, particularmente, nas últimas décadas; no entanto, os fundamentos do MPC, que criam e recriam a pobreza e a desigualdade, permanecem intocados. Segundo ele, de meados do século XIX até os tempos atuais, "conquistas civilizacionais foram feitas", não obstante isso

[...] aquilo que não mudou, todavia, e responde pela permanência da pobreza e da desigualdade, é a dinâmica econômica elementar da nossa sociedade, assentada na acumulação capitalista - por isso mesmo, seus efeitos, os efeitos de sua lei geral, continuam operantes [...]. 
Ao contrário do que sustentam alguns ideólogos, não estamos diante de uma "nova" questão social [mas de] novas expressões da questão social. A "velha" questão social, conotada com o pauperismo, não foi equacionada e, menos ainda, resolvida (NETTO, 2007, p. 155-156).

Esta permanência, da pobreza e da desigualdade, deve-se ao fato delas serem resultado da dinâmica própria do modo de produção comandado pelo capital, e não um fenômeno marginal a ele, ou adjetivo, nem resultado de uma "opção de desenvolvimento", mas resultado do próprio desenvolvimento econômico capitalista. Assim, afirma, “[...] tal permanência [é] produto necessário da acumulação capitalista [e] se opera ao mesmo tempo em que se acentuam os processos de concentração da propriedade e das decisões políticas" (NETTO, 2007, p. 157).

Particularmente na América Latina, impactada pelos “ajustes” do Consenso de Washington, os padrões de pobreza e desigualdade crescem, mas as ações para seu enfrentamento são precarizadas e focalizadas, desenvolvendo-se, assim, "[...] ações minimalistas para enfrentar uma 'questão social' maximizada” (NETTO, 2007, p. 160).

Neste quadro sócio-histórico de crise capitalista e hegemonia neoliberal, de aprofundamento da "questão social" e ampliação e diversificação das formas de expressão da pobreza e da desigualdade social, Netto trata dos desafios profissionais do Serviço Social (NETTO, 2007, p. 164) "[...] um Serviço Social comprometido com a igualdade" (NETTO, 2007, p. 136-138). Para o autor, "[...] nenhuma ação profissional [...] suprimirá a pobreza e a desigualdade na ordem do capital”. Mas seus níveis e padrões podem variar, e esta variação é absolutamente significativa - "[...] e sobre ela pode incidir a ação profissional, incidência que porta as possibilidades da intervenção que justifica e legitima o Serviço Social” (NETTO, 2007, p. 166).

É preciso, para o autor, conhecer os “[...] limites da ação profissional (a impossibilidade de suprimir a pobreza) e as potencialidades (a possibilidade de incidir nos níveis e padrões dessas" (ver NETTO, 2007, p. 166), já que o desconhecimento dos limites conduz ao que lamamoto chamou de "messianismo" ou "voluntarismo" (IAMAMOTO, 1992, p. 113-119), enquanto o desconhecimento das potencialidades leva ao "fatalismo". Isto posto, para o autor, que 
vincula a afirmação e ampliação dos direitos e políticas sociais com a institucionalização do Serviço Social, o desafio profissional central, por um lado, “[...] é a própria ordem social contemporânea [pois,] ao exponenciar a questão social com revigorados dispositivos de produção e reprodução de pobreza e desigualdade, ela os processa mediante a redução e o recorte dos direitos sociais [...]", e, por outro, o de ser capaz de desenvolver "[...] um exercício profissional que, sem ignorar seus limites, amplie suas possibilidades" (NETTO, 2007, p. 167).

\section{A MODO DE CONCLUSÃO}

A contradição como categoria central e a Lei Geral da Acumulação Capitalista na conceituação da gênese da dialética pauperização/ acumulação. Outro aspecto relevante, no nosso estudo, constitui-se do fato do debate do serviço social, muitas vezes, tratar a pobreza como um processo sem contradição.

Como já apontamos, a pobreza nem sempre é caracterizada, no debate profissional, como um processo estrutural, particularizado pelas relações e contradições determinadas no MPC. Tem sido frequente a desvinculação deste processo, a contradição capital-trabalho, dos fundamentos da "questão social" (por exemplo, ao tratar da "multidimensionalidade", da "nova pobreza", ou até dos "riscos" e "vulnerabilidades"), não como fundadas na Lei Geral da Acumulação Capitalista.

Mesmo apresentando a pobreza vinculada a conceitos que a colocam como um lado de uma dada relação social contraditória - necessidade/abundância, carência/riqueza, subalterno/hegemônico, povo/elite, cidadão/não-cidadão, incluído/excluído -, quando tal relação não é entendida a partir da contradição fundante do MPC entre capital e trabalho, esta acaba por ser esvaziada de suas determinações genéticas. No capitalismo, esses processos não podem ser compreendidos criticamente senão como desdobramentos, com suas particularidades (nas formas de desigualdade, nos sujeitos que envolve, na correlação de forças, no tipo de relação que estabelece) de tal contradição capital-trabalho.

Retomar, com toda a força e rigor conceitual, a Lei Geral da Acumulação Capitalista, compreendendo as determinações estruturais do MPC, a 
contradição capital-trabalho, a centralidade da exploração, torna-se um desafio fundamental para o debate do Serviço Social compreender claramente a gênese da pobreza, a dialética acumulação/pauperização, com tanta riqueza, como se compreende as suas manifestações, permitindo, assim, o claro entendimento dos limites e das possibilidades do exercício profissional nas sequelas da "questão social".

\section{REFERÊNCIAS}

ARREGUI, Carola C., WANDERLEY, Mariangela B. A vulnerabilidade social é atributo da pobreza?. Revista Serviço Social \& Sociedade, São Paulo, n. 97, p. 143-165, 2009.

BANCO MUNDIAL. Relatório sobre o desenvolvimento mundial. Washington, 1990.

BANCO MUNDIAL. Relatório sobre o desenvolvimento mundial. Washington, 2000.

BANCO MUNDIAL. Relatório sobre o desenvolvimento mundial. Washington, 2002.

BANCO MUNDIAL. Globalização, crescimento e pobreza. Washington, 2003.

BANCO MUNCIAL. Globalização, crescimento e pobreza: a visão do Banco Mundial sobre os efeitos da globalização. Tradução Melissa Kassner. São Paulo: Futura, 2003.

CACCIA BAVA, Silvio. Perguntas sem respostas. Le Monde Diplomatique Brasil, São Paulo, ano 4, n. 43, fev. 2011.

IAMAMOTO, Marilda. Renovação e conservadorismo no Serviço Social. São Paulo: Cortez, 1992.

. Serviço Social em tempo de capital fetiche: capital financeiro, trabalho e questão social. São Paulo: Cortez, 2007.

IAMAMOTO, Marilda; CARVALHO, Raul de. Relações sociais e Serviço Social. SãoPaulo: Cortez, 1995.

MANDEL, Ernest. La crisis 1974-1980: interpretación marxista de los hechos. México: Serie Popular; Era, 1980.

MARX, Karl. O Capital (Crítica da Economia Política): Livros I, II e III. Rio de Janeiro: Civilização Brasileira, 1980. 
MÉSZÁROS, István. Para além do capital: rumo a uma teoria da transição. São Paulo: Boitempo, 2002.

MONTAÑO, Carlos. Pobreza, 'questão social' e seu enfrentamento. Revista Serviço Social \& Sociedade, São Paulo, n. 110, p. 270-287, 2012.

NETTO, José Paulo. FHC e a política social: um desastre para as massas Trabalhadoras. In: LESBAUPIN, I. (Org.). O desmonte da nação: balanço do governo FHC. Petrópolis: Vozes, 1999. p. 75-79.

NETTO, José Paulo. Desigualdade, pobreza e Serviço Social. Revista Em Pauta, Rio de Janeiro, n. 19, p. 135-170, 2007.

SEN, Amartya. Poverty and Famines: an essay on entitlement and deprivation. Oxford: Oxford Press, 1981.

SEN, Amartya. The standard of living (The tanner lectures). Cambridge: Cambridge University Press, 1990.

SEN, Amartya. Desenvolvimento como liberdade. São Paulo: Companhia das Letras, 2000.

SEN, Amartya. Desigualdade reexaminada. Rio de Janeiro: Record, 2001.

SEN, Amartya. Prefácio. In: GREEN, Duncan. Da pobreza ao poder: como cidadãos ativos e Estados efetivos podem mudar o mundo. São Paulo: Cortez, 2009.

TROTSKY, León. A revolução permanente. São Paulo: Kairós, 1985. YAZBEK, Maria Carmelita. Classes subalternas e assistência social. São Paulo: Cortez, 1996.

YUNUS, M.; JOLIS, A. O Banqueiro dos pobres. São Paulo: Ática, 2001. 